\title{
Financing costs and barriers to entry in Australia's electricity market
}

\begin{abstract}
This article discusses a recent survey of generation sector investors and the associated drivers of the decline in the volume of new-entrant generation, and on generators' weighted-average costs of capital (WACC) and hurdle rates. Over the past year, WACCs have increased for all respondents due to COVID-19-induced financial market disruption, with undiversified/non-integrated participants seeing greater increases in their WACCs than horizontally-integrated participants. Both cost of equity and cost of debt has risen. The survey also investigated the potential impact on WACCs and hurdle rates from a potential introduction of nodal pricing, which was estimated to increase WACCs by 150-200 basis points p.a. (15-20 per cent), due to concerns around the firmness of financial transmission rights and ability to automatically access intraregional settlement residues. These findings have energy policy implications, namely the need to consider the interaction between economic theory and real-world financing models when designing and implementing fundamental energy sector reforms.
\end{abstract}

Keywords: generator access reform, hurdle rates, loss factors, National Electricity Market, renewables, weighted-average cost of capital

JEL Codes: D40; D47; O13; O16; Q40

\section{Introduction}

Australia's national electricity market (NEM) commenced in December 1998, inheriting a highquality and oversupplied stock of monopoly-built utility-scale plant at inception, due solely to significant excess supply of high-capacity factor coal plant. This excess capacity was estimated to be around $4.1 \mathrm{GW}$, or 20 per cent, of baseload capacity installed in $1998 .{ }^{1}$ In contrast, there was a deficit of almost 20 per cent (around 1,500MW) of intermediate and peaking capacity, compared to the optimal amount capacity estimated to be required across the NEM (Simshauser, 2019).

Figure 1 contains the following key trends in relation to the entry and exit of utility-scale (defined as capacity of $100 \mathrm{~kW}$ or greater) plant between the NEM's commencement and end-June 2020:

1. The entry of more than $6,000 \mathrm{MW}$ of gas-fired plant (both intermediate and peaking plant) over the decade to 2009 , with more than half of this capacity (3,600 MW) entering in 2008 and 2009. Rai and Nelson (2019) note this investment occurred in response to both policy signals ${ }^{2}$ and the drought-induced wholesale electricity price spikes of 20072008. ${ }^{3}$ This entry more than filled the estimated shortage of peaking and intermediate capacity at NEM-start, and meant the 2007-2008 wholesale price spikes were only transitory.

2. The exit of high-capacity factor (primarily, coal-fired) plant over a relatively short three-year period (2014-2017); between June 2014 and June 2017 over 4.1 GW of coalfired plant exited the NEM. This exit of plant at-scale unwound all the excess capacity in place at NEM-start, and occurred suddenly and unexpectedly, partly contributing to the doubling in wholesale prices across the NEM between 2016 and 2018 (Rai and Nelson, 2019; Simshauser, 2019).

\footnotetext{
1 This amount of excess baseload capacity meant overall excess capacity in the NEM was almost 10 per cent.

2 These policy signals were the Queensland 18\% Gas Scheme and the NSW Greenhouse Gas Abatement Scheme. The Queensland scheme commenced in January 2005 and required electricity retailers to source 18 percent of their Queensland electricity from gas-fired generation. It was reported that, in the first year of the scheme, over $1600 \mathrm{MW}$ of generation capacity (across ten gas-fired power stations) was accredited (Queensland Government, 2007).

3 In addition to adverse effects on hydro plant, the drought forced some coal-fired generators to mothball units due to cooling water shortages, with urban drinking water being prioritised from affected dams (Simshauser, 2019). 
3. The entry of significant volumes of largely non-dispatchable variable renewable energy (VRE) plant such as wind and solar PV. ${ }^{4}$ Between July 2013 and June 2020, over $10,600 \mathrm{MW}$ of utility-scale wind and solar PV entered the NEM.

\section{Figure 1: Net entry and exit of utility-scale plant across the NEM, by financial year ${ }^{\mathbf{5}}$}

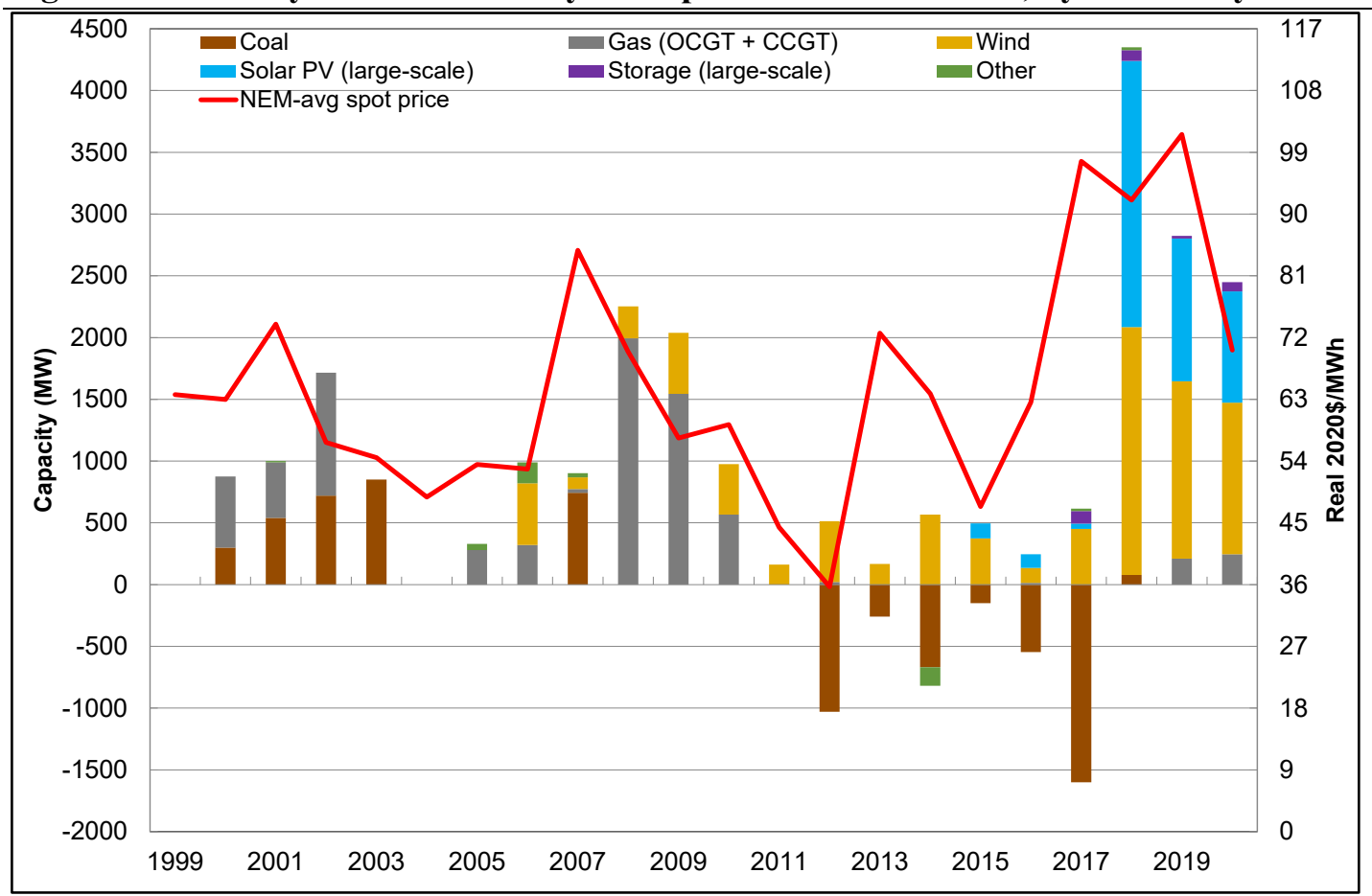

Sources: AEMO, AER.

There are two other key findings from Figure 1:

1. Since June 2018, the volume of new-entrant generation has declined, driven almost entirely by the decline in new-entrant renewables.

2. In terms of non-VRE (i.e. dispatchable ${ }^{6}$ ) plant, there has been a lack of plant entry despite elevated wholesale prices in 2017, in stark contrast to the supply response to the 20072008 price spikes. This lack of entry resulted in wholesale prices remaining at elevated levels over the 2017-2019 period, and well above 2007-2008 prices, with the price decline between 2019 and 2020 reflecting the impact of COVID-19 and lower gas prices, rather than increased plant entry.

The factors attributed to each of these two findings are discussed in Section 4.

Barriers to entry impact financing costs and hurdle rates for prospective generation projects. To better understand the impacts of these cited barriers to entry on financing costs and the availability of debt and equity finance, we conducted a survey of various generation-sector investors. The purpose of this article is to outline the results of this survey and provide insights for policy makers about avoiding unintended consequences of the collision of economic theory with real-world financing considerations.

4 While VRE output can be controlled down, the technical characteristics of existing VRE plant in the NEM means VRE output cannot be controlled up (i.e. increased). Consequently, VRE output is considered non-dispatchable.

5 Prices weighted by volume in each region, and then across regions. Financial year refers to the year ended 30 June.

6 While "dispatchability" does not have a universal meaning, it is commonly considered as the extent to which the resource (i.e. demand or supply resource) can be relied on to 'follow a target' in relation to its load or generation. "Dispatchability" therefore incorporates notions of controllability and flexibility 
This paper is structured as follows: Section 2 provides an overview of the literature on generator financing in the NEM. Section 3 discusses the design of our survey and Section 4 discusses the key findings. Section 5 focuses on one aspect of the survey: the potential impacts of two key policy reforms on WACCs and on hurdle rates. Section 6 discusses the policy implications of the survey results and concludes.

\section{The literature on generator financing in the NEM}

The canonical supply-side business model (Finon, 2008) in the early years of energy market deregulation was the merchant power plant (MPP), a stand-alone generator that sold its output to spot and short-term forward markets (i.e. without long-term contracts or a retail supply business), underpinned by non-recourse project finance (Nelson and Simshauser (2013); Simshauser (2020); Simshauser (2010); Simshauser and Gilmore (2020)). ${ }^{7}$

However, a series of exits and bankruptcies in the US, Europe and Australia rendered the canonical model un-bankable (Finon, 2008; Nelson and Simshauser, 2013). In its place, long-term contracting or vertical integration, sometimes underpinned by government support, emerged as a more viable long-term alternative. This is especially the case for peaking plant, as forecasting peak prices is a harder exercise than flat ('baseload') prices, as peak prices typically occur at times of significant power system imbalance (Simshauser, 2020).

The canonical financing model for VRE plant also involves non-recourse equity and debt project finance ${ }^{8}$, as well as the creation of an off-balance sheet Special Purpose Vehicle (SPV), and a long-dated run-of-plant power purchase agreement (PPA) (Nelson and Simshauser, 2013; Simshauser and Gilmore, 2020b). More recently, a new asset class has emerged in the NEM: merchant VRE, with a financing model akin to the MPP model. It is an open question whether merchant VRE endures or becomes un-bankable much like the canonical MPP model (Simshauser, 2020).

A more sustainable financing model for merchant VRE could be horizontally integrating with fast-start (peaking) plant, as the stochastic nature of VRE output could be as risky to manage as stochastic loads, for which vertical integration with peaking plant emerged as a viable alternative to the canonical MPP model (Simshauser, 2020; Simshauser and Gilmore, 2020b). Expansion of a peaking plant's business boundary, vertically (for stochastic retail loads) or horizontally (for stochastic VRE output), can therefore be a means of achieving effective and efficient risk management.

Given the central role of project finance in facilitating the entry of new plant in the NEM, we surveyed investors in the generation sector to better understand current conditions and trends in relation to the cost and availability of debt and equity finance, as discussed in the next section.

\section{Survey of generation sector investors: design and methodology}

Between April and June 2020, we surveyed investors in electricity generation on the following two themes:

1. The relative importance of various factors cited as preventing the entry of plant into the NEM.

\footnotetext{
7 This was a global trend: from 1997 to 2005, almost 230,000 MW of capacity was added or acquired in the US, most of which was project-financed MPPs (Joskow, 2008). $6000 \mathrm{MW}$ of project-financed plant was added in the UK in the early post-deregulation years (Finon, 2008). In the NEM, between 1998 and 2002, \$18 billion was invested in pre-existing and newly-committed MPPs in the NEM, the vast bulk of which was project-financed.

8 The debt is non-recourse since, in the event of default, the project sponsor is protected to a large extent from creditors, who can only pursue the project's SPV and its assets for remedy purposes. The debt is issued to the project on the strength of the project's expected future cashflows, not by the credit rating of the sponsor (Nelson and Simshauser, 2013).
} 
2. The impact of these barriers to entry on the cost and availability of debt and equity finance, and changes in the availability and cost of finance over the preceding 12 months.

In addition, we asked questions relating to:

- for financing VRE plant, the extent to which an investment-grade off-taker is essential this links in with the merchant VRE trend noted in Section 2, and

- the potential impact on a generation project's weighted-average cost of capital (WACC) from adopting the 'trifecta' of nodal pricing, a firmer access regime, and financial transmission rights (FTRs).

The survey questionnaire was a combination of asking respondents to provide numerical rankings from a closed list of discrete choices, as well as multiple-choice questions of a qualitative or quantitative nature, binary-choice (i.e. yes-or-no) questions, and questions with open-ended qualitative and quantitative answers. The survey questionnaire is provided in Appendix A and B, and the results are discussed in sections 4 and 5.

Responses were sought from the following organisations:

- corporate members of the Clean Energy Council (CEC) - at the time of the survey (July 2019), the CEC had 145 corporate member organisations. Of this, we estimate around half (74) would not be expected to respond to the survey as these organisations are not directly linked to generation investment - organisations such as solar installers, construction companies, and equipment manufacturers ${ }^{9}$; and

- 'full' members of the Australian Energy Council (AEC) - at the time of the survey, the AEC had 28 full member organisations, of which 20 were not members of the CEC. ${ }^{10}$

Of the 91 relevant, non-overlapping, members of the CEC and the AEC that we asked, fifteen responded to the survey, a response rate of $16 \frac{1}{2}$ per cent. Three other organisations, all neither members of the AEC nor the CEC, also responded to the survey. Collectively, these 18 organisations have invested in or operate around one-quarter of installed utility-scale generation capacity in the NEM.

\subsection{Categories of survey respondents}

The survey respondents can be broadly grouped into the following five categories:

1. Project debt financiers

2. Project equity financiers

3. Vertically and/or horizontally-integrated developers of VRE and traditional plant

4. Independent (i.e. non-integrated) VRE developers

5. Independent (i.e. non-integrated) battery storage developers

There is overlap in these categories; certain respondents provide both equity and debt finance to generation projects, while other respondents invest and develop battery storage in conjunction with VRE and traditional (i.e. coal- and gas-fired) plant. Furthermore, some independent developers contract with other developers; for example, wind farms contracting with gas plant to defend fixed-volume hedging contracts such as swaps and caps. Furthermore, one-third of the 18 respondents were foreign-owned domestic subsidiary companies.

In summary, there is a high degree of heterogeneity in the business models and investment strategies and portfolios across the 18 survey respondents. This heterogeneity in the investor base is also found in other parts of the world (Bergek, Mignon and Sundberg, 2013).

\footnotetext{
${ }^{9}$ https://www.cleanenergycouncil.org.au/membership/current-members

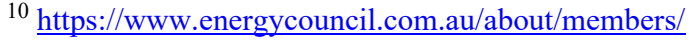




\section{Key findings from the qualitative and quantitative surveys}

\subsection{Qualitative survey: prioritisation of barriers to entry}

This survey asked respondents to rank the relative importance of eleven barriers to entry (see Appendix B). The choice of these barriers was based on factors cited in the academic and industry literature (amongst others, Rai and Nelson (2019); Rai and Nunn (2020); Simshauser (2019); Wood et al., 2018)). The following three issues were cited as the top three entry barriers in relation to investment in VRE plant, in decreasing order of importance (Figure 2):

1. Concerns and challenges related to grid connection process and technical requirements. Grid connection processes require the market operator to undertake extensive assessments of the potential impacts of new plant on system security to inform gridconnection standards. These processes cover issues such as active power and frequency control, reactive power and voltage control, and the fault ride-through capabilities of prospective plant. As noted by Etxegarai et al. (2015), there has been an ongoing trend towards longer and more complicated grid connection processes especially for prospective new-entrant VRE plant given their asynchronous nature, in power systems around the world. The above-cited investor surveys noted these grid connection processes have become more complicated in the NEM since early 2018, coinciding with the increased entry of VRE plant (see Figure 1) and the introduction of new 'do no harm' regulatory requirements for new connections.

Figure 2: Importance of different barriers to entry into the generation sector

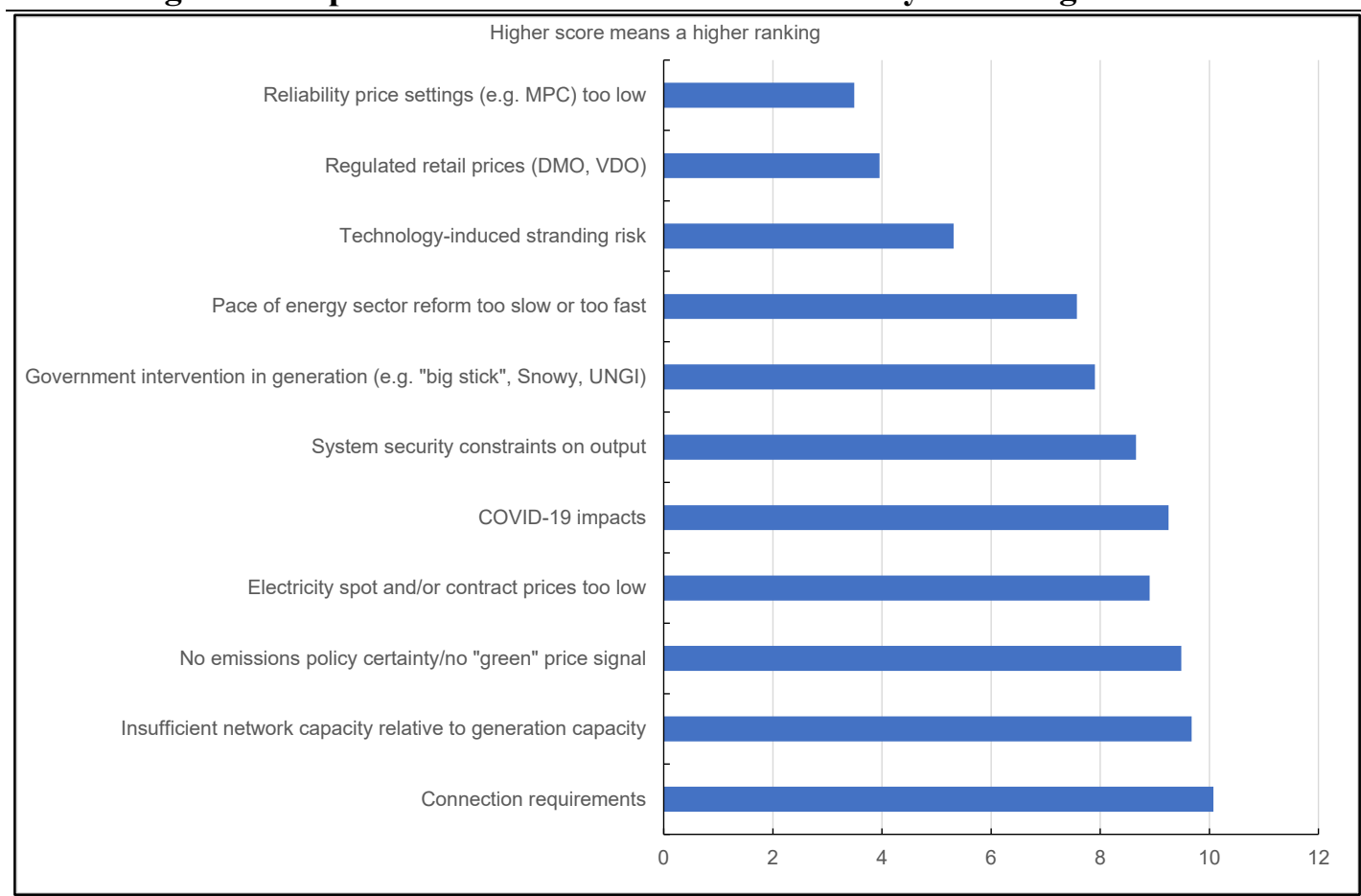

Source: Qualitative survey.

2. An insufficient amount of network capacity relative to the amount of generation capacity installed at some locations. As noted by Rai and Nelson (2019), these issues are particularly acute for VRE plant. Most new-entrant VRE plant have co-located with incumbent VRE plant. The resulting increase in coincident output has, at times, exceeded the (modest) capacity of the transmission network, resulting in both higher congestion and higher electrical losses, the latter exacerbated for wind and solar PV generators due to them locating in areas away from major load centres (in Australia, the best wind and 
solar resources are typically in areas with relatively low amounts of existing network capacity away from major load centres). Examples of these locations include solar PV in far north Queensland, and wind farms in north-west Victoria, with the latter location often referred to as the "rhombus of regret" (White, 2019).

3. A lack of a continued "green" price signal, either in the form of a carbon price or a higher target under the large-scale renewable energy target (LRET), to provide long-term signals for investment in low- and zero-emissions generators. ${ }^{11}$

COVID-19 was acknowledged by all respondents to have created significant barriers to entry via its impacts on:

- increasing financing costs (this is discussed more in section 4.2)

- decreasing electricity demand and creating uncertainty about future electricity demand even after lockdowns are lifted in Australia, and

- the lifecycle cost of VRE generation relative to coal and gas plant, given the significant decline in commodity prices and the expectation that commodity prices might remain subdued for years to come, even after lockdowns are lifted in Australia and globally.

However, COVID-19 was not listed as one of the top 3 entry barriers. All respondents considered COVID-19 impacts were likely to be either transitory or, where more enduring in nature, not as significant in creating barriers to entry as the three listed above.

The findings in Figure 2 are consistent with findings from other industry surveys (Clean Energy Council, 2019; Infrastructure Partnerships Australia, 2019; MinterEllison \& Acuris, 2019). For example, Clean Energy Council (2019)'s survey of its corporate members asked respondents to nominate the top five challenges for developing clean energy projects in Australia. These were:

1. Concerns and challenges related to grid connection process and technical requirements, the top priority in Figure 2

2. Lack of strong federal energy and climate policy (the third priority in Figure 2)

3. Under-investment in network capacity to address congestion and constraints (the second priority)

4. Unjustified government intervention in the energy market, and

5. Lack of certainty about timing of exit of coalfired power stations.

Most of the respondents to the survey were investors in VRE plant. Hence, the survey does not shed as much light on the relative importance of entry barriers vis-à-vis dispatchable plant. In relation to the lack of entry of dispatchable plant (see Figure 1) various studies (e.g. Rai and Nunn (2020), Rai and Nelson (2019), and Simshauser (2019)) have attributed this to a combination of:

- uncertainty on carbon emissions policy, an especially pertinent issue for gas-fired generation which may be stranded under deeper decarbonisation targets. Gas has traditionally been viewed as the 'transitional fuel' for the NEM's decarbonisation but is increasingly viewed as a 'capacity' play to complement higher VRE penetration rates

- higher gas prices and the effects of the drought, which have increased the long-run marginal costs (LRMCs) of prospective gas-fired and run-of-the-river hydro plant, respectively, and meant prices need to be sustained at levels higher than would otherwise be the case, in order for LRMCs to be adequately recovered

- changes in the profile of electricity demand due to the rapid uptake of small- and utilityscale VRE plant. This requires a large amount of VRE-complementary plant (namely,

\footnotetext{
11 The renewable energy target was set at 9.5 terawatt hours (TWh) by 2010. In January 2011, a target of 41TWh by 2020 was set, but in June 2015 was subsequently revised down to 33 TWh by 2020 . This annual amount remains unchanged through to 2030, which is when the LRET is scheduled to end (Rai and Nelson, 2019). 
fast-start, fast-response, lower-capacity factor, plant), as opposed to slow-start, highcapacity factor plant

- technology-induced stranding risk, in particular the risk that batteries may become cheaper than peaking plant (gas-fired or pumped hydro). In California, 4-hour batteries are increasingly replacing gas peaking plant as these plant approach major capital expenditures (associated with extensions of technical life). 6-hour storage also poses stranding risk to more intermediate/less peaking plant (Spector, 2019), and

- various government interventions into the wholesale and retail market, including underwriting new-entrant plant and the entry of Snowy 2.0. Snowy 2.0, a 2000MW pumped hydro plant, would compete directly with other forms of fast-start dispatchable plant and is expected to enter the market from the mid-to-late 2020s. This timeframe is, unfortunately, long enough to elongate otherwise-transitory price spikes (such as in Figure 1), but short enough to make stranding risk a material issue for private investors.

\subsection{Quantitative survey: changes in WACCs and hurdle rates, and availability of finance}

Across all survey respondents, the key findings from the quantitative survey can be summarised as follows (Figure 3):

1. Over the year to end-April 2020, WACCs and hurdle rates had increased for all respondents.

2. An investment-grade PPA off-taker was not viewed as essential to obtaining debt finance on reasonable terms, a finding somewhat at odds with the reported increase in financing costs. Since 2017, merchant VRE as a new asset class first emerged and then grew, as noted in section 2 . Between 2017 and 2019, 18 PV $(\sim 1.5 \mathrm{GW})$ and 5 wind $(\sim 0.9 \mathrm{GW})$ fully merchant projects reached financial close. A further 10 existing wind plants $(\sim 0.6 \mathrm{GW})$ have found themselves with merchant exposures as inaugural 10-15 year PPAs had run full-term (Simshauser, 2020). ${ }^{12}$

3. What-if analysis of WACC impacts (discussed in more detail in section 5): in particular, what if the existing regional pricing regime was replaced by nodal pricing with financial transmission rights (FTRs), as proposed by the Australian Energy Market Commission (AEMC)'s co-ordination of generation and transmission investment (COGATI) reforms. All respondents considered this would increase their WACCs.

\section{WACCS}

The survey revealed WACCs for diversified players were in the order of 8-10\% p.a. at the time of the survey, compared to 11-14\% p.a. for undiversified participants. This is consistent with the general finding that corporate finance WACCs are lower than project-specific WACCs due to the diversification benefit offered by the former, especially under non-recourse project finance (Wiser, 1997; Simshauser, 2010; Helms, Salm and Wüstenhagen, 2015).

This risk-reduction benefit was also observed in terms of trends in WACCs over time. Over the preceding 12 months, WACCs had increased the most for those survey respondents who were undiversified (e.g. developers of and investors in single technologies).

Furthermore, cost of equity was the bigger driver of the increase in WACCs than the cost of debt. While the cost of debt had risen in March 2020 due to the fear of corporate defaults induced by the COVID-19 pandemic, the liquidity injections by the Reserve Bank of Australia had becalmed markets to an extent.

\footnotetext{
${ }^{12}$ Furthermore, several cum-PPA VRE entrants have oversized entry capacity, thereby acquiring residual merchant exposures $(\sim 650 \mathrm{MW})$. 
Figure 3: Key findings from the quantitative survey, by question

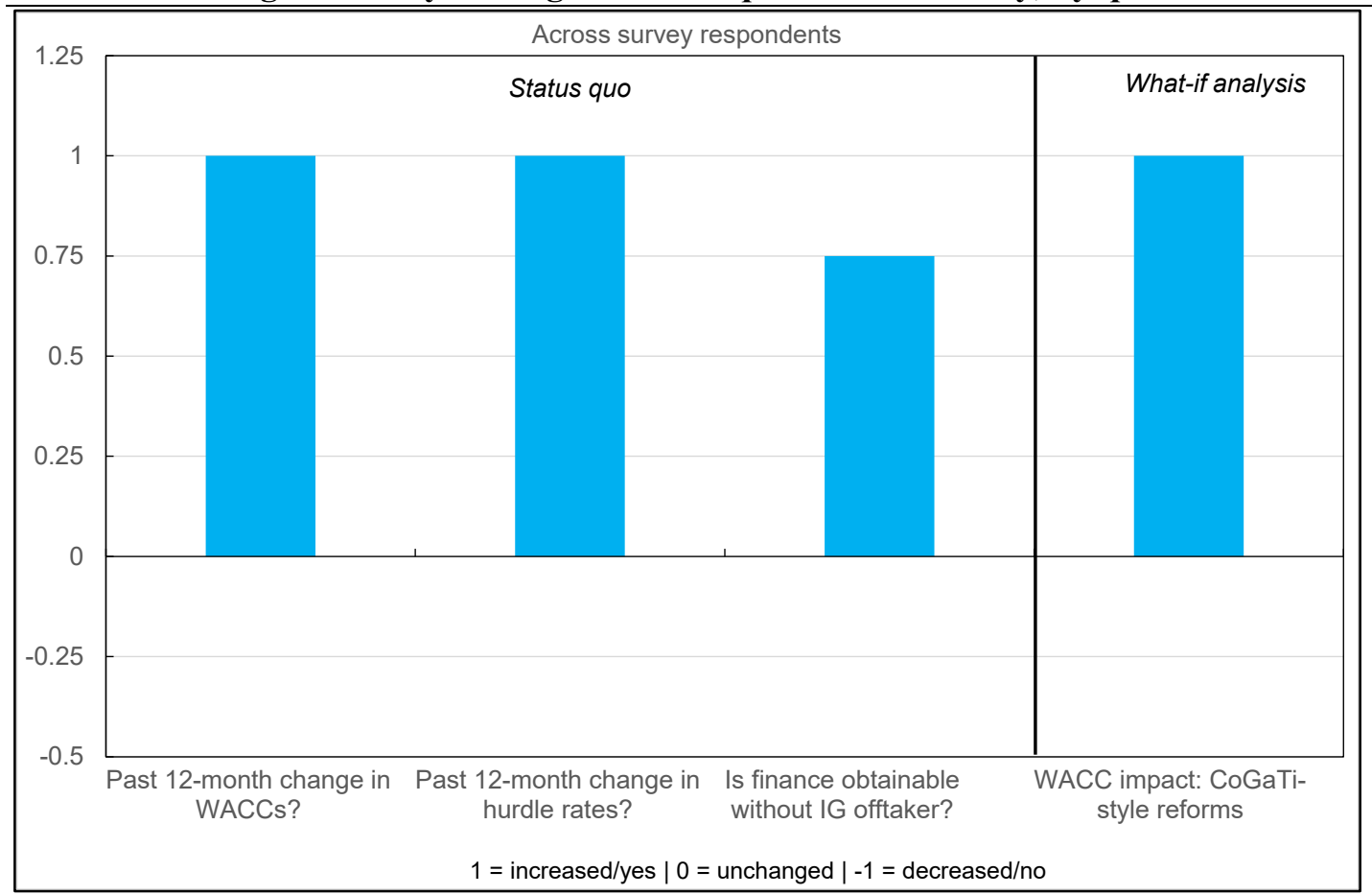

Source: Quantitative survey.

In addition to portfolio effects, the range in WACCs also reflected project-specific drivers such as the extent of contracting, the credit quality of the counterparty, and the type of technology (Wiser, 1997; Simshauser, 2010, 2020; Helms, Salm and Wüstenhagen, 2015). For example, WACCs for solar PV developers had risen by a larger amount than WACCs for wind developers, a finding attributed to the higher risk of coincident output-induced congestion and losses (i.e. a higher 'correlation penalty') for solar PV vis-à-vis wind as documented by, amongst others, Hirth (2013).

These findings are consistent with other studies that examine the impact of asset diversification on the costs of project and corporate finance (also noted in Helms et al., 2015; Simshauser, 2020, 2010; Simshauser and Gilmore, 2020; Wing Lee and Zhong, 2015; Wiser, 1997).

\section{Hurdle rates}

Similar to WACCs, hurdle rates had increased for all respondents especially once the COVID-19 pandemic hit. Hurdle rates are an order of magnitude larger than WACCs, with reported hurdle rates of $14-20 \%$ p.a. across the set of respondents. As expected and similar to WACCs, hurdle rates were lower for respondents with integrated (horizontally and/or vertically) businesses, and highest for independent solar and wind developers.

That hurdle rates are higher than WACCs is a finding not unique to the electricity sector: similar dynamics exist in other sectors, both in Australia and overseas (Figure 4). Furthermore, hurdle rates are often held constant through time, rather than being adjusted in line with changes in WACCs. For example, two-thirds of firms review their hurdle rates less frequently than their WACCs, and nearly half of firms rarely change their hurdle rate (Truong, Partington and Peat, 2008; Lane and Rosewall, 2015).

Internationally, the WACC-hurdle rate differential is above the differential in Australia (Mejorado and Roman, 2017; Lowe, 2019). For example, the hurdle rate amongst American nonfinancial corporates was around 14 per cent p.a. in 2019, compared to a cost of debt of 2 per cent 
p.a. (Figure 4). This differential was even greater in the Euro area $\left(13 \frac{1}{2}\right.$ per cent p.a. hurdle rate vs. $0.5 \%$ p.a. cost of debt). The 'stickiness' of hurdle rates is also evident.

These findings raise the question: why are hurdle rates so much higher than WACCs? Survey respondents considered that, in short, risk is currently underpriced in the following ways:

- hurdle rates incorporated additional debt $\&$ equity risk premia than what was being priced in the market. In this regard, the market gyrations associated with COVID-19 was cited as an example of unexpected upwards repricing of risk which therefore necessitated a need to allow for future potential upwards repricing of risk, and hence a higher hurdle rate vis-à-vis the WACC

- in terms of debt, interest rates and spreads are expected to 'normalise' over generation projects' (long) lives. Respondents considered this debt repricing could be in the order of 300-350 basis points, raising annual debt costs from 2 per cent currently towards $5 \frac{1}{2}$ per cent in future. Rather than facing this refinancing risk if or when this occurred at some future time, survey respondents were pricing this risk into today's hurdle rates

- similarly, on the equity side, equity risk premia were also expected to normalise in the order of 200-250 basis points at some point over the project's life, and

- risks that the market are either under-pricing or not pricing. A key risk cited of regulatory and political intervention - noting that electricity is an essential commodity that means this risk is more material than for other capital-intensive sectors, which was expected by survey respondents to add 200-250 basis points to the hurdle rate. Other risks cited include technology risks and carbon policy risks (both mitigation and adaptation risks), which are hard to hedge or diversify, and are likely to intensify over projects' lives given the ongoing efforts to increase decarbonisation targets and abatement ambition.

Figure 4: Hurdle rates and the cost of debt for non-financial corporates

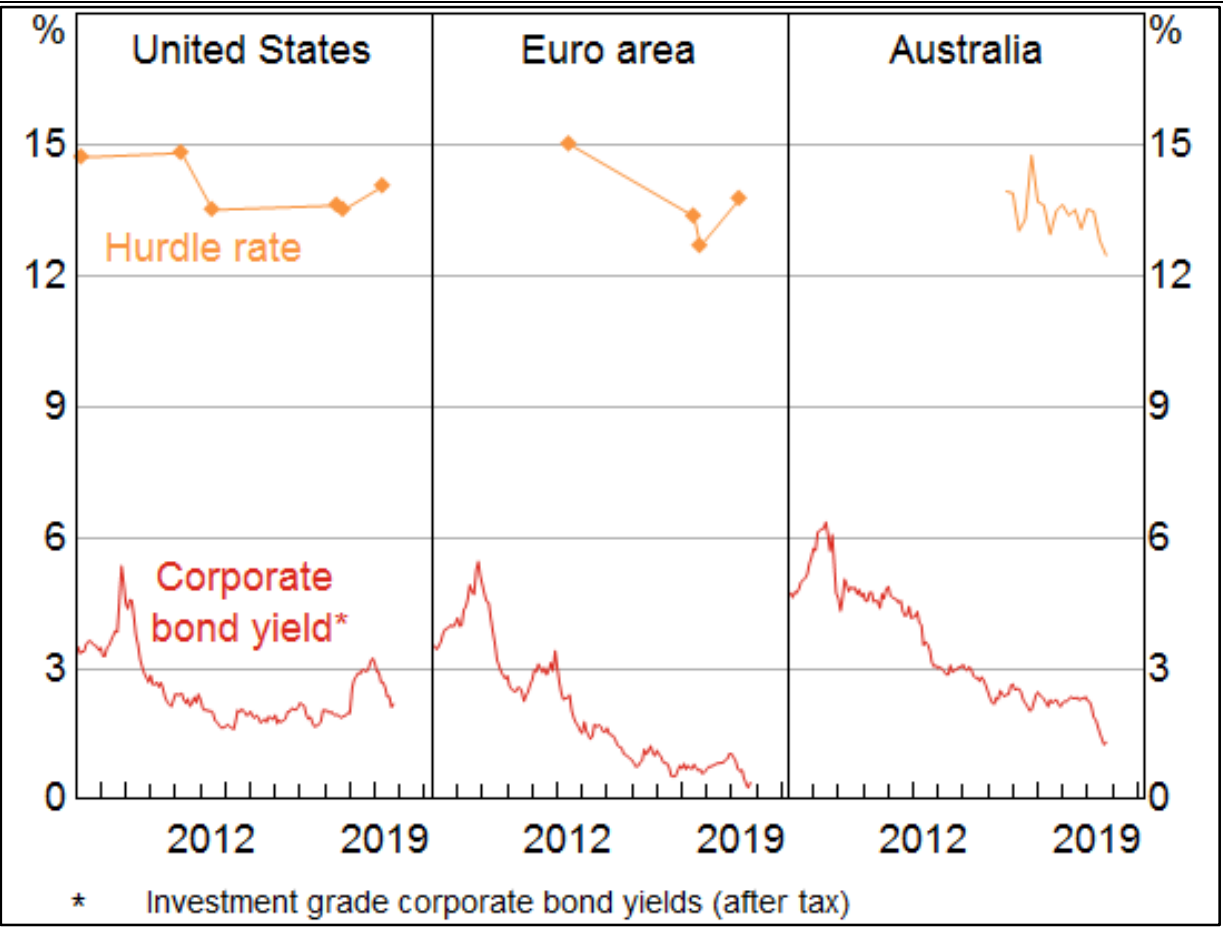

Source: Figure 8 from Lowe (2019)

Other reasons attributed to the hurdle rate-WACC differential include (Lane and Rosewall, 2015): 
- being as a measure to overcome potential optimism bias in cash flow projections, as well as to account for uncertainty about the cash flow projections, and

- a "set and forget" mentality to hurdle rates, with today's hurdle rates often set during the high interest rate, pre-Global Financial Crisis, era. This also helps explain the 'stickiness' of hurdle rates evident in Figure 4.

Collectively, these drivers explain the 500-600 basis point differential between WACCs and hurdle rates. These findings are consistent with other studies on the electricity sector, both within Australia (Naughten, 2003; Simshauser, 2010, 2020; Simshauser and Gilmore, 2020b) and internationally (Wiser, 1997; Wambach, 2000).

\subsubsection{Trends in the cost of debt and cost of equity}

The costs of debt finance for generation projects are not publicly available; instead, estimates of these costs can be obtained by examining the cost of debt for BBB-rated non-financial corporates. BBB is the credit rating for (Simshauser, 2010; Simshauser and Gilmore, 2020b):

- PPAs to be bankable, in which case PPAs must be written by a counterparty with an investment grade credit rating (i.e. $\geq B B B-$ ), and

- $\mathrm{BBB}$ is typically the credit rating for those electricity businesses that have credit ratings (for example, AGL Energy and Origin Energy)

After reaching record lows in January 2020, debt costs for BBB-rated non-financial corporates doubled between February and April 2020 reflecting the disruption caused by COVID-19. As at end-June 2020, the 5-year BBB spread to government bonds was at 197 basis points, a 64 per cent increase from January 2020 levels (120 basis points), down from an April peak of 240 basis points (Figure 5).

Figure 5: BBB-rated non-financial 5-year corporate bond yields and spreads

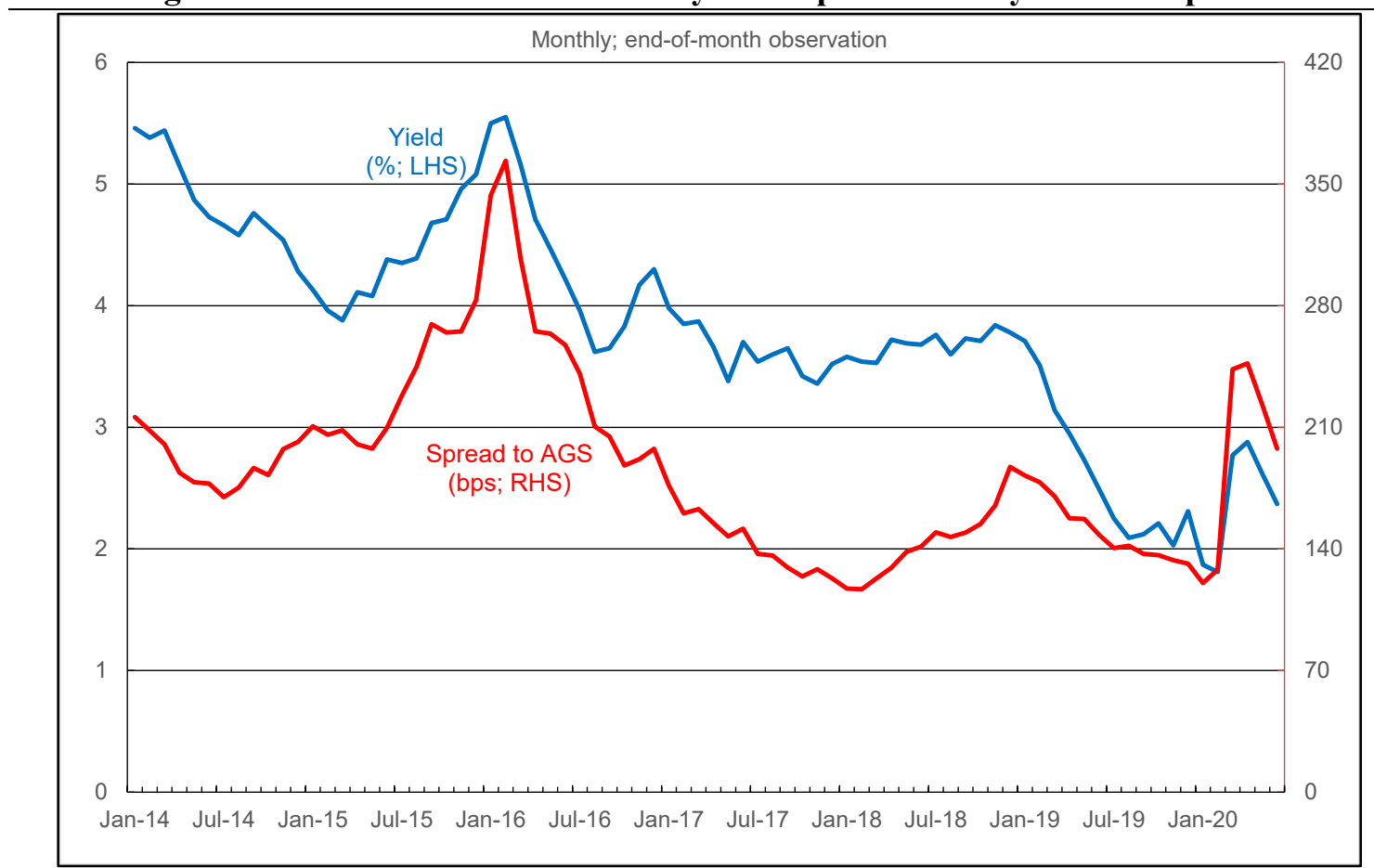

Note: AGS is Australian Government Securities i.e. bonds issued by the Australian Commonwealth Government Source: Reserve Bank of Australia

While survey respondents noted BBB spreads were not a good proxy of debt costs for those projects without a credit rating, they agreed that current debt costs were at record lows. 


\section{Potential impact of adoption of nodal pricing on generators' WACCs}

The AEMC, via its COGATI process, has proposed three inter-related fundamental changes to the current design of the NEM's wholesale market (AEMC, 2019a):

1. Adoption of nodal pricing for generators, enabled by a full network model of losses and congestion, with load-weighted nodal prices for loads

2. Financial transmission rights (FTRs) to hedge unexpected differences ('basis risk') between a generator's nodal price and the regional reference price (RRP)

3. Consequential changes to the access regime for generators and other measures as required to provide sufficient firmness to the FTRs.

As noted by Gregan and Read (2008) generators in the NEM presently hold an implicit right to be settled at the regional reference node (RRN), thereby being protected from congestion-induced price basis risk within that region. Therefore, the effect of regional pricing is that some of the intra-regional settlement residues (IRSRs) - which arise when prices are not the same in all locations within a region - are paid to, or in the case of negative IRSRs paid by, intra-regional generators.

Specifically, in a market with regional pricing, every generator is paid the RRP - the clearing price at the RRN - regardless of the price at the generator's node (or 'nodal price'). Consider, for each and every five-minute dispatch interval $t$ within a given 30 -minute trading interval $k$, the revenue (Rev) of generator $h$ in (1), with the generator located at node $i$ in region $j$, with dispatched volume $Q_{h, i}^{j}$, and a nodal price $P_{i}^{j}$ and RRP of $P_{R R N}^{j}$ (ignoring electrical losses): ${ }^{13}$

$$
R e v_{h, i, t}^{j, k}=P_{R R N, t}^{j, k} \cdot Q_{h, i, t}^{j}=P_{i, t}^{j} \cdot Q_{h, i, t}^{j, k}+\left(P_{R R N, t}^{j, k}-P_{i, t}^{j}\right) \cdot Q_{h, i, t}^{j}
$$

Under nodal pricing, the generator's revenue is only the first term $\left(P_{i, t}^{j} \cdot Q_{h, i, t}^{j}\right)$; under regional pricing, revenues also include the second term. That is, under regional pricing, generator $h$ receives some of the residues whenever $\left(P_{R R N, t}^{j, k}-P_{i, t}^{j}\right) \cdot Q_{h, i, t}^{j} \neq 0$. In turn, for a given dispatch volume $Q_{h, i, t}^{j}>0,\left(P_{R R N, t}^{j, k}-P_{i, t}^{j}\right) \neq 0$ when network congestion and/or losses occur.

In the NEM, not all of the IRSRs are available to generator $h$; in particular, most of the residues attributable to physical losses are unavailable to generators (Frontier Economics, 2008; Gregan and Read, 2008; Biggar and Hesamzadeh, 2014). Generators in the NEM are settled on the basis of static MLFs, which are an annual volume-weighted average of dynamic (i.e. five-minute) losses, with loss factors inversely related to the level of losses (AEMO, 2012, 2017). ${ }^{14}$

In contrast, most loads are settled on an MLF of 1 . Therefore, the amounts generators receive are not equal to what loads pay; the resulting IRSR is allocated to consumers by corresponding changes to transmission prices.

This said, some of the losses-induced IRSRs are allocated to generators since MLFs are a static representation of 'dynamic' loss factors (DLFs). Therefore, the nodal price with MLFs is not the same as the nodal price with DLFs. Including losses in (1) gives (2):

$$
\begin{aligned}
\operatorname{Rev}_{h, i}^{j, k} & =P_{R R N, t}^{j, k} \cdot M L F_{h, T}^{j} \cdot Q_{h, i, t}^{j} \\
& =\left(P_{i, t}^{j} \cdot D L F_{h, i, t}^{j} \cdot Q_{h, i, t}^{j}\right)+\left(P_{R R N, t}^{j, k}-P_{i, t}^{j}\right) \cdot D L F_{h, i, t}^{j} \cdot Q_{h, i, t}^{j}
\end{aligned}
$$

\footnotetext{
${ }^{13}$ Currently, the RRP used for settlement purposes is the equal-weighted average of the six dispatch interval RRPs within that trading interval (with the trading interval starting either on the hour or half-past the hour), for each region $j$. That is, $P_{R R N, t}^{j, k}=\frac{1}{6} \sum_{t=1}^{6} P_{R R N, t}^{j, k}$, for a given trading interval $k$. From 1 October 2022, the settlement RRP in the NEM will be set at the five-minute RRP; i.e. $P_{R R N, t}^{j, k}=P_{R R N, t}^{j}$ and equations (1)-(3) would need to be modified accordingly.

${ }^{14}$ More precisely, the loss factor $L F_{h, i}^{j}=\left(1-l_{h, i}^{j}\right)$, where $l_{h, i}^{j}$ is the losses, on a per-MW basis, associated with generator $h$ 's output.
} 


$$
+\left(P_{R R N, t}^{j, k} \cdot M L F_{h, i, T}^{j}-P_{R R N, t}^{j, k} \cdot D L F_{h, t}^{j}\right) \cdot Q_{h, i, t}^{j}
$$

The first line in (2) is the revenue under existing pricing arrangements for settlement purposes in the NEM: regional prices based on marginal loss factors (MLFs). The second line disaggregates this into revenue attributable to (for each and every five-minute dispatch interval $t$ ):

- the nodal price with congestion and dynamic losses included: $\left(P_{i . t}^{j} \cdot D L F_{h, i, t}^{j} \cdot Q_{h, i, t}^{j}\right)$. Reflecting its dynamic nature, the dynamic loss factor $\left(D L F_{h, i, t}^{j}\right)$ varies every five minutes (just like $P_{i, t}^{j}$ and $Q_{h, i, t}^{j}$ )

- the congestion-induced IRSRs allocated to the generator, for a given (dynamic) loss factor: $\left(P_{R R N, t}^{j, k}-P_{i, t}^{j}\right) \cdot D L F_{h, i, t}^{j} \cdot Q_{h, i, t}^{j}$. This term is similar to the second term in (1) though with losses included in (2) but not in (1), and

- the losses-induced IRSRs allocated to the generator under regional pricing vis-à-vis nodal pricing: $\left(P_{R R N, t}^{j, k} \cdot M L F_{h, i, T}^{j}-P_{R R N, t}^{j, k} \cdot D L F_{h, t}^{j}\right) \cdot Q_{h, i, t}^{j}$

An MLF is a static representation of electrical losses associated with the transport of energy from generators to loads. In particular, a generator's MLF is the generation-weighted average of its DLF over a financial year; that is, for financial year $T$ :

$M L F_{h, i, T}^{j}=\left[\frac{1}{\sum_{t=1}^{17,520} Q_{h, i, t}^{j}} \sum_{t=1}^{17,520} Q_{h, i, t}^{j} \cdot D L F_{h, i, t}^{j}\right]$

Equations (1) and (2) provide important context for understanding the survey results with respect to the "what-if?" question in relation to moving from regional pricing to nodal pricing-cumfinancial transmission rights (FTRs). All survey respondents noted such a move would increase their WACCs (Figure 6) by 150-200 bps p.a.

Figure 6: Effect on WACC from adopting nodal pricing reforms

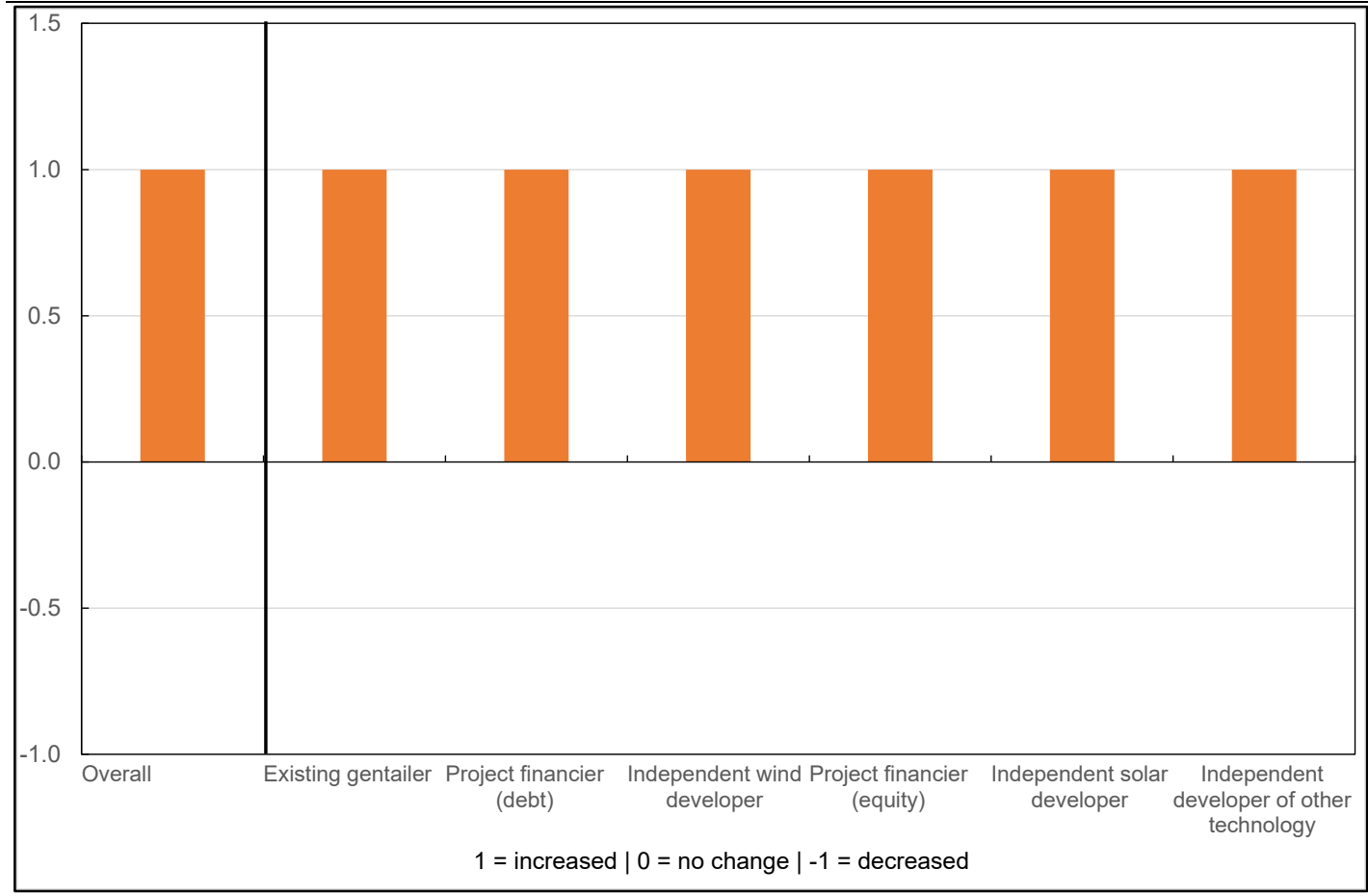

Source: Quantitative survey. 
In turn, the WACC impacts are largely influenced by the extent to which generators automatically access IRSRs.

In the absence of FTRs, nodal pricing would decrease generator revenues as generators would no longer receive IRSRs for free. This would be especially so for those generators located in areas with high export congestion and/or high losses (Frontier Economics, 2008; Gregan and Read, 2008; Read and Jackson, 2013; Biggar and Hesamzadeh, 2014):

- the second term in equation (2) would be eliminated by allowing for congestion-induced price differentials between the local price and the RRP. For generators in exportcongested areas, the local price would be less than the RRP, and

- the third term in equation (2) would be eliminated by incorporating DLFs, rather than static weighted-average approximations of DLFs (i.e. MLFs). For generators in areas with a high level of losses, the local price would be less than the RRP.

The proposed COGATI reforms provides financial transmission rights (FTRs) as the means by which generators can, if they opt to, receive the IRSRs. With FTRs in place, some of the forgone IRSR revenue to generators can be made up via FTR payouts when congestion and/or losses arise. However, FTRs would cost generators money and therefore, on balance, generators would be worse off. Conversely, consumers would be better off since the proceeds from the FTR auctions would be returned to consumers via reduced network prices, with the IRSRs accruing under nodal pricing being used to fund FTR payouts.

Volume-based basis risk under regional pricing - that is, the risk of being constrained-on or constrained-off - is converted into price-based basis risk under nodal pricing. This price risk can be perfectly hedged (at a cost to generators) with FTRs provided the FTRs are of sufficient firmness and duration (Gregan and Read, 2008; Read and Jackson, 2013; Biggar and Hesamzadeh, 2014; AEMC, 2019a). AEMC (2019a) proposes fixed-volume FTR options resulting in the following modification of a generator's revenue from equation (2):

$\operatorname{Rev}_{h, i, t}^{j, k}=P_{i, t}^{j} \cdot D L F_{h, i, t}^{j} \cdot Q_{h, i, t}^{j}+\max \left(0, P_{R R N, t}^{j, k} \cdot M L F_{h, i, T}^{j}-P_{i, t}^{j} \cdot D L F_{h, i, t}^{j}\right) \cdot F T R_{h, i}^{j}$

where $\max (0, \cdot)$ reflects the payout on the FTR option, $F T R_{h, i}^{j}$ is the volume of FTRs held by generator $h$, and all other terms are as per equation (2). The one-sided nature of the FTR payout is designed to make generator $h$ no worse off under nodal pricing. However, this only applies if there is no cap on FTR payouts. If, instead, FTR payouts are limited by the available residues, the FTRs are no longer firm, since if negative IRSRs were to arise the FTRs would need to be scaled down until the residues were no longer negative. This would undermine FTR firmness, and consequently revenue volatility may be no lower under nodal pricing vis-a-vis regional pricing.

As the survey respondents noted, the following well-known issues in relation to the design of FTRs are also prevalent in the AEMC's COGATI design:

- Revenue adequacy and the firmness of FTRs. Revenue adequacy relates to the extent to which the settlement residue amounts are not lower than the payments under all the FTR in a given time period. FTRs are revenue-adequate when the implied power flows from the FTRs are "simultaneously feasible" (Hogan, 2002, 2005; Frontier Economics, 2008; Biggar and Hesamzadeh, 2014). Revenue adequacy is assured both ex-ante (i.e. at the time FTRs are auctioned) and ex poste (i.e. at times when FTRs pay out) if the power flows assumed in the FTR's formulation and auctioning stages are realised in practice.

Survey respondents expressed concern that revenue adequacy analysis had not yet been undertaken by the AEMC, with simultaneous feasibility studies not proposed to be conducted until the second half of 2020 (AEMC, 2019a). Concerns about revenue adequacy amongst survey respondents were especially high in relation to the existing constraints on asynchronous plant output in electrically-weak parts of the NEM. These 
constraints have been imposed relatively recently - since last September - and unexpectedly (AEMO, 2019). Due to their unexpected nature, survey respondents considered these network constraints may have resulted in revenue inadequacy (and subsequent non-firmness) of FTRs had FTRs been in place during this time, given the AEMC proposed that potential shortfalls that could occur if/when FTR payouts exceed the IRSR amounts should not be paid for by any entity (such as the network business).

- Point-to-point (PTP) vs. flowgate (FG) FTRs. FG FTRs are constraint-by-constraint hedges that give the FTR holder the right to collect payments based on the shadow price associated with a particular transmission constraint (or 'flowgate') while PTP FTRs provide a hedge between named injection and withdrawal nodes (Hogan, 2002; Kristiansen, 2004; Frontier Economics, 2008; Gregan and Read, 2008; Biggar and Hesamzadeh, 2014). Some designers (e.g. Hogan (2002)) consider PTP FTRs to be firmer than FG FTRs; others prefer FG FTRs (Kristiansen, 2004), with no consensus in the literature. Respondents to the investor survey preferred PTP FTRs due to the former's relative ease of understanding and broader applicability internationally, and were concerned with the AEMC's preference for a (quasi form of) FG FTRs (AEMC, 2019a).

- FTR obligations vs options. FTR obligations means FTR holders are obliged to pay when the FTR's value is negative, as well as a right to be paid when the FTR's value is positive. In contrast, FTR options give holders the option to avoid making payments when the FTR's value is negative (Hogan, 2002, 2005; Kristiansen, 2004; Frontier Economics, 2008; Biggar and Hesamzadeh, 2014). Survey respondents agreed with the AEMC's preference for FTR options.

For FTR options to be sufficiently firm, residue shortfalls (i.e. negative IRSRs) need to be funded by an entity, which is typically the provider of the transmission network service at the relevant node(s) (Biggar and Hesamzadeh, 2014). Survey participants were concerned with the AEMC's preference for residue shortfalls to not be funded by any entity, implying a lack of firmness in the FTR options.

- The volumes settled under an FTR. An FTR can create volume-based basis risk when the volumes settled under an FTR differs from the volume settled in the spot market (i.e. $F T R_{h, i}^{j} \neq Q_{h, i, t}^{j}$ in equation (4)) or the volume settled under hedging contracts. Fixedvolume FTRs can create volume risk for VRE plant and other variable-volume plant such as peakers. Survey respondents were concerned with the AEMC's preference for fixedvolume FTRs (AEMC, 2019a).

In addition, survey respondents expressed concerns about the proposed duration of FTRs: three to four years at most (AEMC, 2019a). The short duration of FTRs relative to the duration of plant (30+ years) was seen to create "FTR rollover" risk in terms of the impact of changes in FTR prices on generator revenues and profits at the time of FTR rollover.

Together, concerns about the firmness and duration of FTRs explains why all survey respondents considered the proposed COGATI reforms would increase their WACC and regardless of the extent to which the respondent was diversified vertically or horizontally (Figure 6). In contrast, one-fifth of respondents considered adopting ALFs would not reduce their WACC. These participants include those that have plant with MLFs greater than 1, whose revenues would be negatively impacted by having a lower loss factor (i.e. based on ALFs), despite the increased automatic access to IRSRs (i.e. a firmer implicit FTR) available under an ALF methodology.

As noted above, insufficiently-firm FTRs means revenue volatility is higher under nodal pricing vis-à-vis regional pricing. In turn, increased revenue volatility increases the WACC, a wellknown effect documented in the corporate finance literature (Modigliani and Miller, 1958; Miller, 1988). This explains the finding in Figure 6 in relation to the proposed COGATI reforms. 


\section{Conclusion and policy implications}

The preceding discussion has the following overarching policy implication: policies should be oriented towards reducing the major entry barriers as efficiently as possible, as follows:

- policy makers should focus efforts on enhancing the insufficient amount of network capacity in ways that minimise the risk to consumers of overbuilding and asset stranding. In this regard, ongoing efforts by Australian policymakers to streamline and quicken regulatory investment tests, within the context of an Integrated System Plan that adequately incorporates Australia's climate change objectives, are appropriate and welcomed (ESB, 2019a)

- following on from the last point, policy should be targeted towards the problems at hand. The AEMC's COGATI reforms do not directly incentivise more transmission network investment, as there is no link between transmission network planning and investment on the one hand, and FTR prices and purchases on the other (AEMC, 2019a). Instead, AEMO's integrated system plan provides the signal for the amount, timing, and location of new network investment. This suggests policy makers should focus less on COGATI, and more on the ISP, as the means for enabling additional network investment

- the prior point implies the benefits of COGATI would solely relate to requiring generators to pay for the IRSRs they receive for free under existing regional pricing. The freely-allocated IRSRs, which accrue largely because of congestion, is estimated to be around $\$ 300$ million per year (Katzen and Leslie, 2020). Our survey results reveal the COAGTI reforms would increase financing costs by 150-200 bps p.a., which would dwarf these potential savings to consumers

- policy to provide certainty on emissions reduction targets and mechanisms for the electricity sector are necessary, to provide signals for investment in low- and zeroemissions generators. There is ongoing research on the need to design VRE production subsidies in a manner that overcomes some of the inefficiencies and distortions that can arise under technology-specific policies (Nelson, Rai and Esplin, 2020), and

- policy makers should ensure reforms do not in themselves create barriers to entry, which can occur when policy design is incomplete and/or policy implementation is too fast or too slow. This is relevant for the proposal to introduce nodal pricing into the NEM.

While we are not convinced that the COGATI reforms are necessary, we note that consideration of the need for nodal pricing-cum-FTRs has another policy implication: the need to integrate market design with real-world financing models in a manner that reflects, to the extent possible, the physics of the power system. Policy integration has the following dimensions:

- FTR design that is aligned with the output of plant in order to enhance FTR firmness and thereby increase the FTR's effectiveness in hedging price basis risk. Such alignment can be achieved if:

O the volumes settled under a generator's FTR equal the dispatched volumes; that is, $Q_{h, i, t}^{j}=F T R_{h, i}^{j}$ in equation (4), for each and every dispatch interval $t$. This is especially the case for variable-output plant such as VRE plant, as well as midmerit and peaking plant. If $Q_{h, i, t}^{j} \neq F T R_{h, i}^{j}$, FTR payouts may not exactly offset the reduction in revenues from losing access to IRSRs under regional pricing, resulting in increased revenue volatility for generators under nodal pricing

- having an entity cover any ex post revenue inadequacy. Inadequacy arises when actual power flows differ from what was forecast at the time the FTRs were auctioned. In turn, measures to redress revenue inadequacy means $Q_{h, i}^{j} \neq F T R_{h, i}^{j}$ as FTRs are scaled down to reflect a lower-than-expected IRSR (Biggar and 
Hesamzadeh, 2014). A logical entity for covering revenue inadequacy could be the transmission network service provider for that node

- The need to respect existing generators' rights to automatically access the congestion component of IRSRs under the status quo regional pricing. These rights, which are accrued rights as they have existed since NEM-start, would be respected if FTRs were grandfathered (i.e. FTRs allocated to existing generators free of charge) for a period of time, after which all generators would be required to purchase FTRs.

- The need to bring stakeholders "along the journey". At its December 2019 meeting, the COAG Energy Council instructed the AEMC to work with market participants in the design of its COGATI model. However, as noted in section 5.2, market participants do not support COGATI due to their concerns about the lack of FTR firmness and the need to pay for access to the IRSRs under nodal pricing which they receive for free under the existing regional pricing framework. There is also little support for COGATI from consumer groups, as the reforms are not relevant to the major issues facing energy consumers (see Rai and Nelson, 2019).

- The need to give market participants sufficient time before implementing fundamental reforms such as moving from regional to nodal pricing. A sufficiently long preimplementation period is necessary given the following financing considerations:

- recognising that financing models for generation projects has changed over time, from the canonical model of the MPP (Finon, 2008) to one based on long-term contracting or vertical integration (see Section 2). Fundamental reforms implemented too quickly creates the risk of triggering force majeure clauses in long-term contracts and can therefore be a source of regulatory risk, and

o understanding that generation projects are financed with relatively short-term debt (typically, a 5 to 7-year tenor). Furthermore, even long-term hedge contracts typically have durations lower than the useful lives of plant. ${ }^{15}$ Introducing or proposing fundamental reforms that do not have all the requisite design considerations fleshed out and supported by stakeholders can create refinancing and re-contracting risks for existing projects, increasing the risk of asset stranding and debt default especially under short pre-implementation periods. Debt providers may not wish to rollover debt until they understand the postreform picture. Therefore, policy changes may not only affect future investment, but may also affect the value and operations of existing assets.

At the heart of the proposed COGATI reforms policy is a crucial question: to what extent does adding complexity to the determination of spot prices improve economic outcomes? Complexity increases risk and potentially creates further barriers to entry in what is already an oligopolistic NEM. This would need to be weighed against any potential benefits of improved locational decisions by new participants (as existing congestion will need to be grandfathered).

In relation to the need for sufficient time for implementation, the AEMC initially proposed a start date of 01 July 2022 for nodal pricing and FTRs (AEMC, 2019c). While seemingly giving market participants three years to design the necessary market and regulatory arrangements, the proposed implementation date had the effect of impacting all projects today: incumbent, new-entrant, and proposed. The impact on incumbent projects reflects the significant debt refinancing task required, with $\$ 18 \mathrm{bn}$ of project debt $(\$ 8.4 \mathrm{bn})$ and corporate debt $(\$ 9.6 \mathrm{bn})$ needing to be refinanced between 2020 and 2025 (Simshauser and Gilmore, 2020a) (Figure 7).

\footnotetext{
${ }^{15}$ For example, most LRET-eligible plant have PPAs that expire at the end of 2030, which is when the LRET is scheduled to end. In contrast, even the earliest LRET-eligible plant (installed in the early 2000s) have useful lives of 5-10 years after the end of their PPAs.
} 
These considerations also apply for other big-picture policy reforms, such as the Energy Security Board (ESB)'s work on the design of retail and wholesale markets of the NEM, where potentially fundamental changes to the energy-only design of the wholesale market are being considered (ESB, 2019b). In the context of the proposed COGATI reforms, it will be important to consider whether additional renewables would be inhibited, and the cost of new-entrant plant increased, by the additional complexity added through nodal pricing-cum-FTRs.

Figure 7: Expected refinancing of VRE project debt, 2019-2030

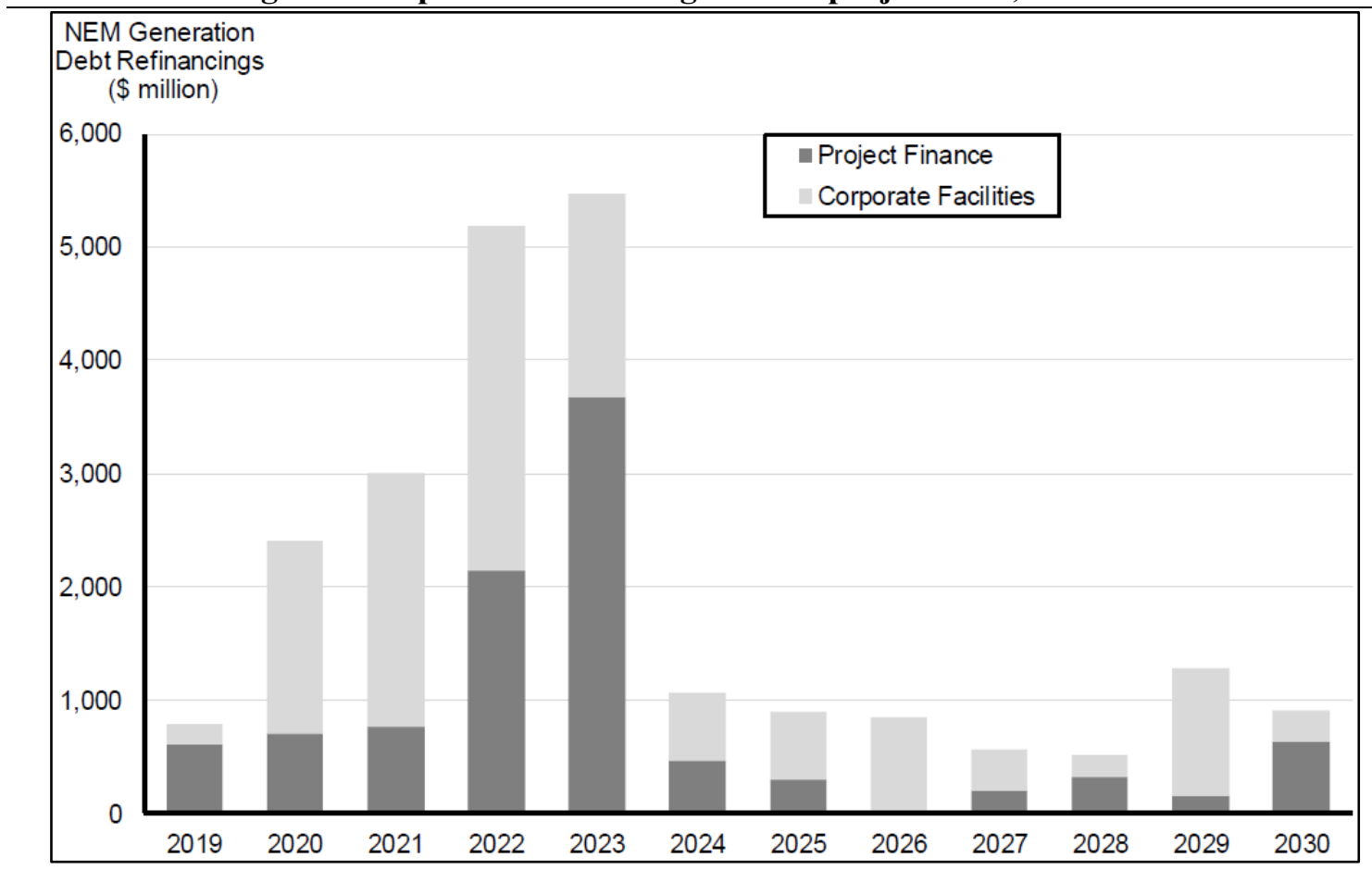

Source: Figure 17, Simshauser and Gilmore (2020a)

The AEMC responded to stakeholder concerns on the proposed implementation date for COGATI by proposing a timeframe of at least four years from the time of changing the regulatory framework for generator access. This timeframe is beyond the three-year duration of commonlytraded hedging contracts, and allows time for longer-term contracts to be renegotiated and integrated with FTR designs and negotiations. The AEMC has also proposed ways to increase the firmness of FTRs by, for example, having proceeds from FTR purchases be added to IRSRs, to reduce the potential for revenue inadequacy, rather than be directly returned to consumers via lower network charges (AEMC, 2019b).

A longer-term implementation date was also adopted by the AEMC when it set a 43-month timeframe for introducing a major reform related to aligning settlement prices with dispatch prices. This timeframe was designed to give industry time to adjust to this fundamental change impacting spot and contract markets, metering and IT systems - balancing the need to capture the benefits of moving to 5-minute settlement as soon as possible against the costs and risks associated with transitioning too quickly. This timeframe has also provided industry sufficient time to build and develop new fast-response generation technologies.

Overall, policy makers need to pragmatically consider the interaction between:

- real-world financing, cognisant of how the canonical financing model of a hypothetical MPP (Finon, 2008) has been replaced with long-term contracting

- economic theory, in relation to providing efficient price signals to ensure the right types of resources are built at the right times at the right locations, and 
- physics: the need to align financial incentives with physical system needs, as well as the risks to reliability and security from rushing implementation of fundamental reforms.

\section{References}

AEMC (2019a) Coordination of generation and transmission investment - proposed access model. Available at: https://www.aemc.gov.au/sites/default/files/2019-10/EPR0073 - COGATI Proposed Access Model - Discussion paper.pdf.

AEMC (2019b) Coordination of generation and transmission investment - update paper. Available at: https://www.aemc.gov.au/sites/default/files/documents/cogati_update_paper_final_1.pdf.

AEMC (2019c) Coordination of generation and transmission investment implementation - access and charging. Available at: https://www.aemc.gov.au/market-reviews-advice/coordination-generation-andtransmission-investment-implementation-access-and.

AEMO (2012) Treatment of loss factors in the national electricity market, Technical Report. Available at: https://aemo.com.au/-

$/ \mathrm{media} /$ files/electricity/nem/security_and_reliability/loss_factors_and_regional_boundaries/2016/treatment _of_loss_factors_in_the_nem.pdf.

AEMO (2017) Forward-looking transmission loss factors. Available at: https://aemo.com.au//media/files/electricity/nem/security_and_reliability/loss_factors_and_regional_boundaries/2017/forwardlooking-loss-factor-methodology-v70.pdf.

AEMO (2019) Power system limitations in north-western Victoria and south-western New South Wales. Available at: https://www.aemo.com.au/-/media/Files/Electricity/NEM/Network_Connections/PowerSystem-Limitations-December.pdf.

Bergek, A., Mignon, I. and Sundberg, G. (2013) 'Who invests in renewable electricity production? Empirical evidence and suggestions for further research', Energy Policy, 56(May), pp. 568-581. doi: https://doi.org/10.1016/j.enpol.2013.01.038.

Biggar, D. R. and Hesamzadeh, M. R. (2014) The economics of electricity markets. 1st edn. New York: Wiley-IEEE Press. Available at: https://ieeexplore.ieee.org/book/6898621.

Clean Energy Council (2019) Confidence index, Confidence index. Available at: https://assets.cleanenergycouncil.org.au/documents/resources/reports/clean-energy-outlook/clean-energycouncil-confidence-index-dec-2019.pdf.

ESB (2019a) Consultation on draft ISP rules, Consultation paper. Available at: http://www.coagenergycouncil.gov.au/publications/consultation-draft-isp-rules.

ESB (2019b) Post 2025 market design issues paper. Available at: http://www.coagenergycouncil.gov.au/sites/prod.energycouncil/files/publications/documents/EC - Post 2025 Market Design Issues Paper - 20190902_0.pdf.

Etxegarai, A. et al. (2015) 'Review of grid connection requirements for generation assets in weak power grids', Renewable and Sustainable Energy Reviews. Elsevier, 41, pp. 1501-1514. doi: 10.1016/j.rser.2014.09.030.

Finon, D. (2008) 'Investment risk allocation in decentralised electricity markets. The need of long-term contracts and vertical integration', OPEC Energy Review, 32(2), pp. 150-183. Available at: https://doi.org/10.1111/j.1753-0237.2008.00148.x.

Frontier Economics (2008) Generator nodal pricing - a review of theory and practical application. Available at: https://www.aemc.gov.au/sites/default/files/content/8e474690-be29-408d-93a58d5e7b4601df/Frontier-Economics-Generator-Nodal-Pricing-Review-of-a-Report-by-FrontierEconomics.pdf.

Gregan, T. and Read, E. G. (2008) Congestion pricing options for the Australian national electricity market: overview. Available at: https://www.aemc.gov.au/sites/default/files/content/37b3afa2-c4bc-46f7$836 \mathrm{a}-\mathrm{a} 7 \mathrm{~b} 4358 \mathrm{fb} 0 \mathrm{fd} /$ Congestion-Pricing-Options-for-the-Australian-NEM-Overview-by-Tendai-Greganand-E-Grant-Read-February-2008.pdf. 
Helms, T., Salm, S. and Wüstenhagen, R. (2015) 'Investor-specific cost of capital and renewable energy investment decisions', in Donovan, C. W. (ed.) Renewable energy finance: powering the future. World Scientific, pp. 77-101. doi: 10.1142/P1030.

Hirth, L. (2013) 'The market value of variable renewables: The effect of solar wind power variability on their relative price', Energy Economics, 38(July), pp. 218-236. Available at: https://doi.org/10.1016/j.eneco.2013.02.004.

Hogan, W. W. (2002) Financial transmission right formulations. Cambridge, Massachusetts 02138. Available at: http://www.lmpmarketdesign.com/papers/FTR_Formulations_033102.pdf.

Hogan, W. W. (2005) 'Transmission market design', in Griffin, J. M. and Puller, S. L. (eds) Electricity deregulation: choices and challenges. 1st edn. Chicago: Chicago Scholarship Online, pp. 358-386. doi: 10.7208/chicago/9780226308586.003.0010.

Infrastructure Partnerships Australia (2019) 'Australian infrastructure investment report', (November). Available at: https://infrastructure.org.au/aus-infra-investment-report-2019/.

Joskow, P. (2008) 'Capacity payments in imperfect electricity markets: need and design', Utilities Policy, 16(3), pp. 159-170. Available at: https://doi.org/10.1016/j.jup.2007.10.003.

Katzen, M. and Leslie, G. (2020) Revisiting optimal pricing in electrical networks over space and time: mispricing in Australia's zonal market, SSRN Electronic Journal. doi: 10.2139/ssrn.3501336.

Kristiansen, T. (2004) 'Markets for financial transmission rights', Energy Studies Review, 13(1), pp. 25-74. doi: 10.15173/esr.v13i1.467.

Lane, K. and Rosewall, T. (2015) Firms' investment decisions and interest rates, Reserve Bank of Australia Bulletin. Sydney. Available at: https://www.rba.gov.au/publications/bulletin/2015/jun/pdf/bu0615.pdf\#page $=3$.

Lowe, P. (2019) Some echoes of Melville - Sir Leslie Melville lecture 2019, Reserve Bank of Australia. Available at: https://www.rba.gov.au/speeches/2019/sp-gov-2019-10-29.html.

Mejorado, A. and Roman, M. (2017) 'Profitability and secular stagnation: the missing link', International Journal of Political Economy, 46(2-3), pp. 150-166. doi: 10.1080/08911916.2017.1383686.

Miller, M. H. (1988) 'The Modigliani-Miller propositions after thirty years', Journal of Economic Perspectives, 2(4), pp. 99-120. doi: 10.1257/jep.2.4.99.

MinterEllison \& Acuris (2019) Australian renewable energy investment trends and outlook. Available at: https://www.minterellison.com/articles/australian-renewable-energy-sector-investment-outlook.

Modigliani, F. and Miller, M. H. (1958) 'The cost of capital, corporation finance and the theory of investment', The American Economic Review, 48(3), pp. 261-297. doi: 10.1257/aer.103.4.i.

Naughten, B. (2003) 'Economic assessment of combined cycle gas turbines in Australia: some effects of microeconomic reform and technological change', Energy Policy, 31(3), pp. 225-245. doi: 10.1016/S03014215(02)00031-9.

Nelson, J. and Simshauser, P. (2013) 'Is the merchant power producer a broken model?', Energy Policy. Elsevier, 53, pp. 298-310. doi: 10.1016/j.enpol.2012.10.059.

Nelson, T., Rai, A. and Esplin, R. (2020) Overcoming the limitations of VRE production subsidies as a means of decarbonising electricity markets.

Queensland Government (2007) Queensland gas scheme proves a winner, The Minister for Mines and Energy, Media release. Available at: http://statements.qld.gov.au/Statement/2007/4/3/queensland-gasscheme-proves-a-winner.

Rai, A. and Nelson, T. (2019) 'Australia's national electricity market after twenty years', Australian Economic Review, pp. 1-18. doi: 10.1111/1467-8462.12359.

Rai, A. and Nunn, O. (2020) 'Is there a value for "dispatchability" in the NEM? Yes', The Electricity Journal, 33(April), p. 106712. Available at: https://doi.org/10.1016/j.tej.2020.106712.

Read, E. G. and Jackson, P. R. (2013) 'Experience with FTRs and related concepts in Australia and New Zealand', in Rosellón, J. and Kristiansen, T. (eds) Financial Transmission Rights. Lecture Notes in Energy, 
volume 7. London: Springer, pp. 305-332. doi: 10.1007/978-1-4471-4787-9.

Simshauser, P. (2010) 'Vertical integration, credit ratings and retail price settings in energy-only markets: navigating the resource adequacy problem', Energy Policy, 38(11), pp. 7427-7441. Available at: https://doi.org/10.1016/j.enpol.2010.08.023.

Simshauser, P. (2019) Lessons from Australia's national emlectricity Market 1998-2018: the strengths and weaknesses of the reform experience. Available at: https://ideas.repec.org/p/cam/camdae/1972.html.

Simshauser, P. (2020) Merchant renewables and the valuation of peaking plant in energy-only markets. 2002. Available at:

https://www.researchgate.net/publication/338435403_Merchant_renewables_and_the_valuation_of_peakin g_plant_in_energy-only_markets.

Simshauser, P. and Gilmore, J. (2020a) Is the NEM broken? Policy discontinuity and the 2017-2020 investment megacycle. Available at: https://www.eprg.group.cam.ac.uk/wp-content/uploads/2020/05/2014Text_UPD.pdf.

Simshauser, P. and Gilmore, J. (2020b) 'On entry cost dynamics in Australia's national electricity market', Energy Journal, 41(1), pp. 259-287. doi: 10.5547/01956574.41.1.psim.

Spector, J. (2019) What comes next after batteries replace gas peakers?, Greentech Media. Available at: https://www.greentechmedia.com/articles/read/california-clean-power-outlook-what-comes-after-shorterduration-batteries.

Truong, G., Partington, G. and Peat, M. (2008) 'Cost-of-capital estimation and capital-budgeting practice in Australia', Australian Journal of Management, 33(1), pp. 95-121. Available at: https://doi.org/10.1177/031289620803300106.

Wambach, A. (2000) 'Payback criterion, hurdle rates and the gain of waiting', International Review of Financial Analysis. doi: 10.1016/S1057-5219(00)00028-4.

White, A. (2019) 'Generators lose battle to cut power loss penalty', The Australian, 13 November. Available at: https://www.theaustralian.com.au/business/mining-energy/generators-lose-battle-to-cutpower-loss-penalty/news-story/c64a2f8a60fb5237f8cf96d489f4586b.

Wing Lee, C. and Zhong, J. (2015) 'Financing and risk management of renewable energy projects with a hybrid bond', Renewable Energy, 75(March), pp. 779-787. Available at: https://doi.org/10.1016/j.renene.2014.10.052.

Wiser, R. H. (1997) 'Renewable energy finance and project ownership', Energy Policy, 25(1), pp. 15-27. Available at: https://doi.org/10.1016/S0301-4215(96)00115-2.

Wood, T., Blowers, D. and Percival, L. (2018) Mostly working: Australia's wholesale electricity market. Available at: https://grattan.edu.au/report/mostly-working/. 


\section{A. Survey questionnaire - trends in the availability and cost of finance}

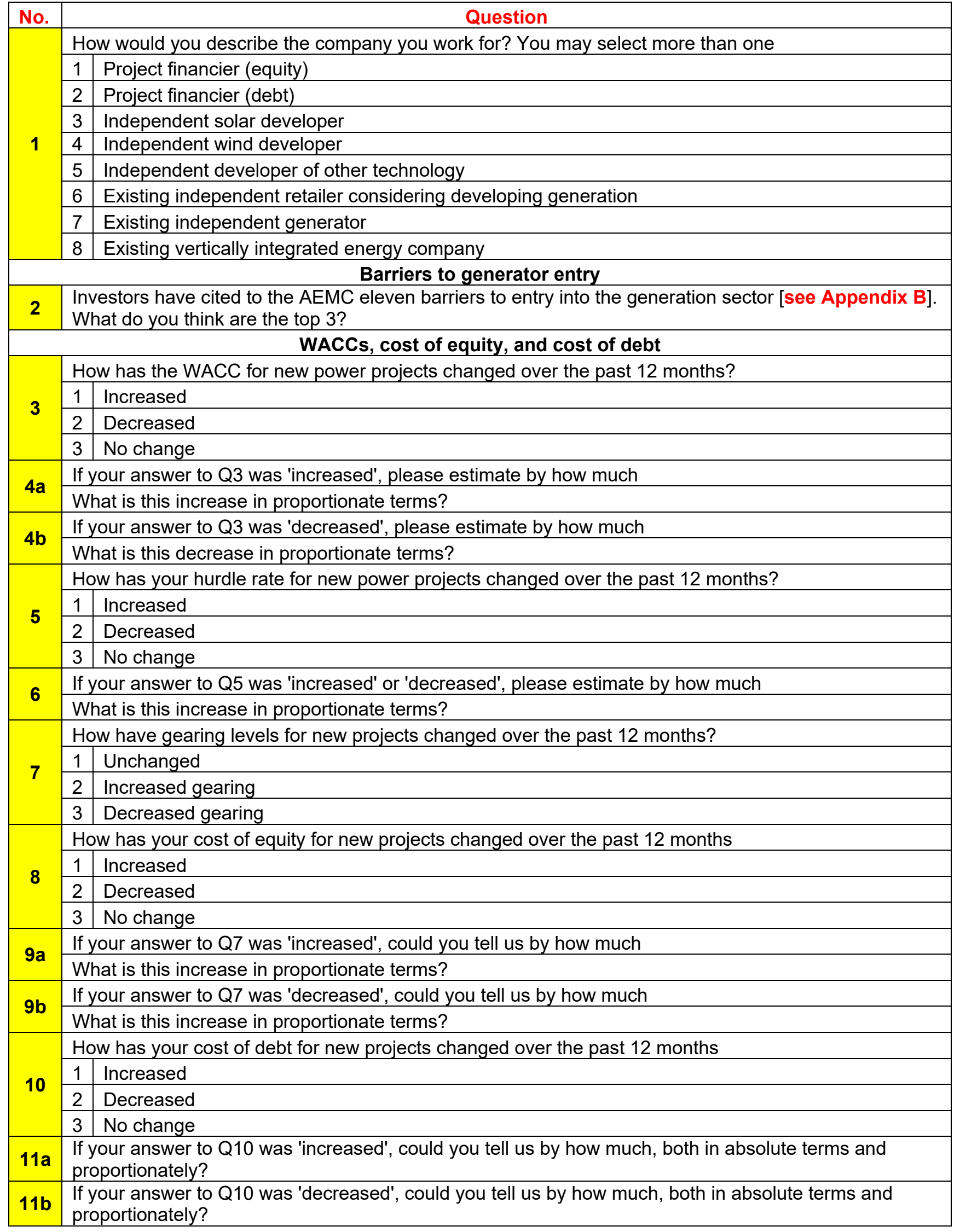




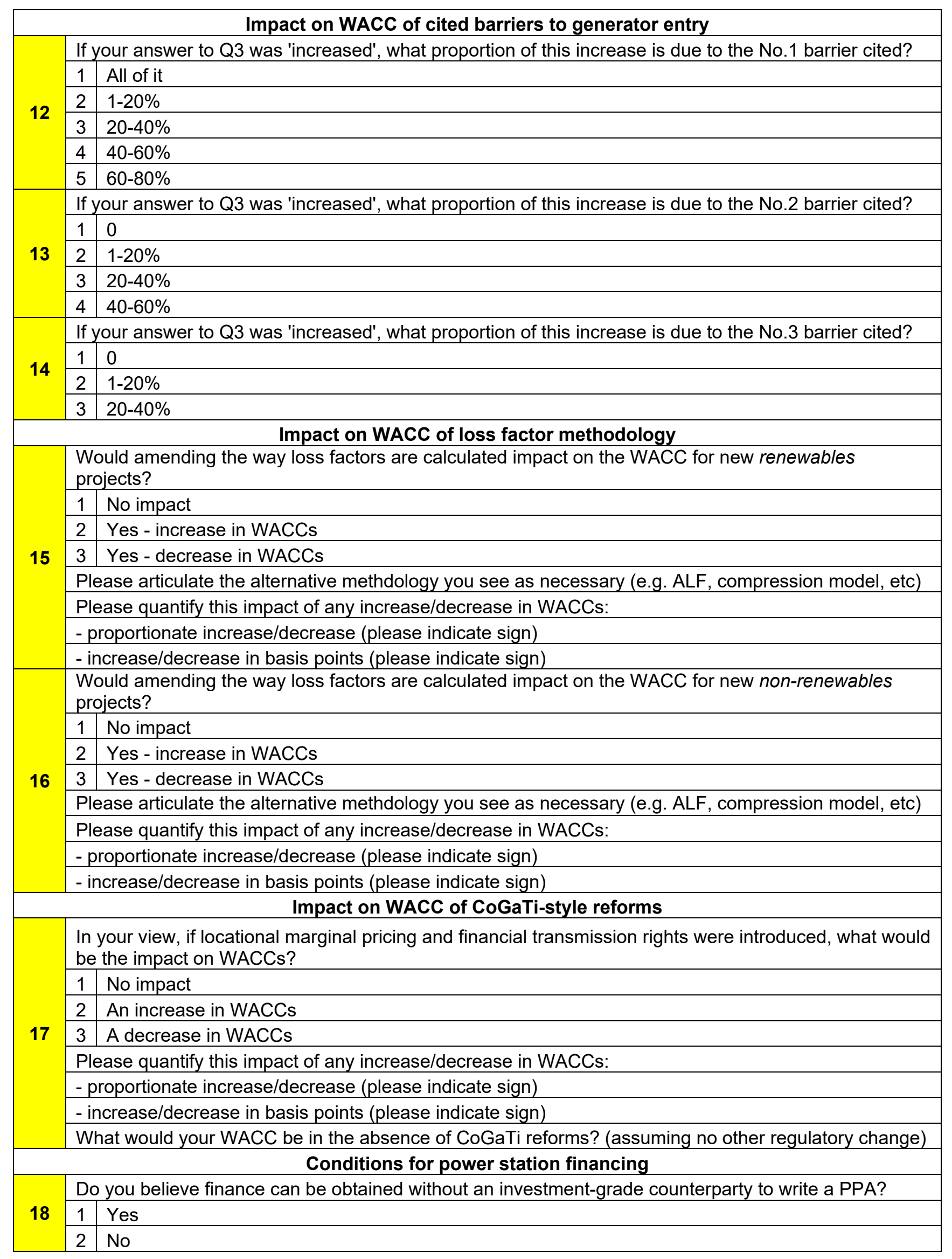




\section{B. Survey questionnaire - barriers to entry}

\begin{tabular}{|c|c|c|}
\hline Item & Cited barrier to entry & Ranking* \\
\hline 1 & Government intervention in generation (e.g. "big stick", Snowy, UNGI) & \\
\hline 2 & Connection requirements & \\
\hline 3 & Pace of energy sector reform too fast or too slow & \\
\hline 4 & $\begin{array}{l}\text { Impact of COVID-19 on generation costs and on current/future electricity } \\
\text { demand }\end{array}$ & \\
\hline 5 & No emissions policy certainty/no "green" price signal & \\
\hline 6 & Electricity spot and/or contract prices too low & \\
\hline 7 & Technology-induced stranding risk & \\
\hline 8 & Regulated retail prices (DMO, VDO) & \\
\hline 9 & Reliability price settings (e.g. MPC) too low & \\
\hline 10 & System security constraints on output & \\
\hline 11 & Insufficient network capacity relative to generation capacity & \\
\hline \multicolumn{3}{|c|}{ * $1=$ most important; $11=$ least important } \\
\hline
\end{tabular}

